MATEC Web of Conferences 7, 02008 (2013)

DOI: $10.1051 /$ matecconf $/ 20130702008$

(C) Owned by the authors, published by EDP Sciences, 2013

\title{
Friction Melt Bonding: An innovative process for aluminium-steel lap joints
}

\author{
Aude Simar, Camille Van Der Rest and Pascal J. Jacques \\ Université catholique de Louvain, iMMC, IMAP, Louvain-la-Neuve, Belgique
}

\begin{abstract}
A new process based on Friction Stir Welding has been developed to weld dissimilar metals, particularly steel and aluminum, in a lap-joint configuration. In this Friction Melt Bonding process, frictional heat generated by the rotating and translating tool brings about local and transient melting (Figure 1). Welding then occurs owing to controlled reactivity and solidification at the interface between the two plates. With an adequate choice of the welding parameters, low alloy steel and aluminium alloys have been successfully welded. Characterisation of the microstructure was systematically performed to highlight the influence of the process parameters, particularly the temperature cycle, on the steel-Al interface. The thickness of the intermetallic layer varies from a couple of micrometers to tens of micrometers depending on the advancing speed of the tool (Fig. 2). The lap shear properties of the joints were also investigated and analysed based on the morphology of the intermetallic layer.
\end{abstract}

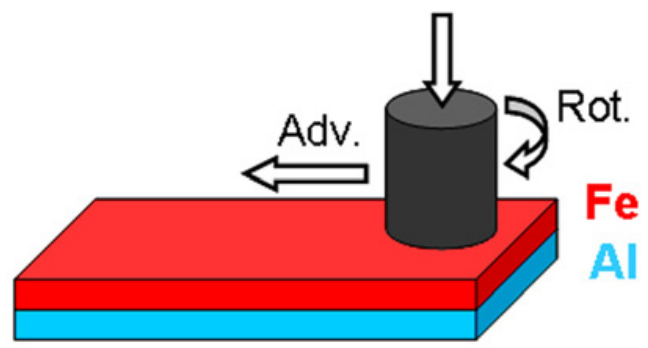

Figure 1. Principle of the friction melt bonding process.

\section{References}

Aude Simar, Camille van der Rest, Pascal J. Jacques; Method for welding at least two layers; Patent Application $\mathrm{N}^{\circ}$ : $12166124.3-2302$.

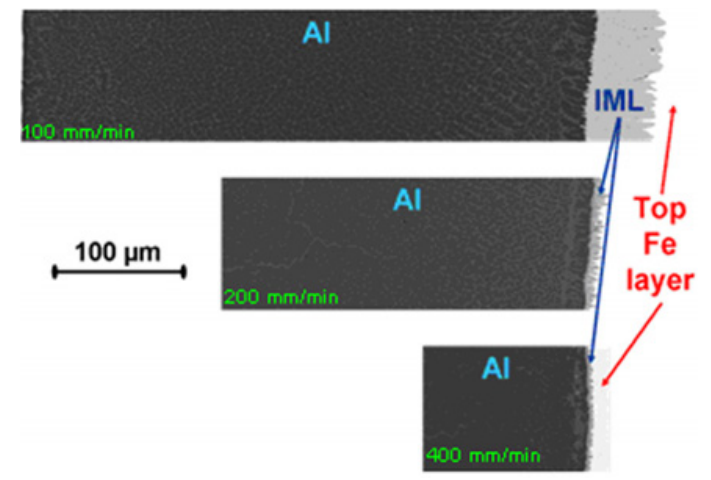

Figure 2. Effect of the advancing speed on the thickness of the intermetallics layer. 